\section{SCIENTIFIC LITERATURE}

\section{Information for Chemists}

A NEW service called Access has been announced by Chemical Abstracts Service which will help chemists and librarians to locate specific journals, monographs, books or patent specifications containing information of chemical or chemical engineering interest. The first edition, to be published in October in two volumes costing $\$ 100$, will contain details of the holdings of some 20,000 periodicals and monographs published since 1830 in 400 libraries all over the world. This literature represents a 62-year cumulation of titles covered by Chemical Abstracts, including discontinued periodicals and those no longer covered by $C A$; it also includes additional titles in pure and theoretical chemistry covered by Chemisches Zentralblatt between 1830 and 1940, and several hundred pre-1907 titles covered by Beilstein's Handbuch der Organischen Chemie. Supplements reporting new or previously unlisted titles (with information on library holdings) and bibliographic changes from previous listings will be issued quarterly as a subscription service (costing $\$ 75$ a year) beginning in December 1969. The fourth quarterly supplement, to be issued in September of each year, will cumulate all changes for the year. Both the first edition and the supplements will also be available on magnetic tape for computer searching and updating.

The listings in Access will indicate which of the participating libraries hold particular volumes of the publications, with the complete title in the original language of the publication, and an English translation (if the original is in a language other than English, French, German or Spanish), the United States Standards Institute abbreviation for the title, references to any previous titles by which the publication has been known, and details of publication history, frequency of issue, price if the item is still in print, and so on. There will also be a special section on holdings of patent specifications, an index of names and addresses of participating libraries with details of interlibrary loan and photocopy services and a directory of publishers and sales agents.

To some extent, Access will be like the list of Periodicals Abstracted by Chemical Abstracts which has been issued at regular intervals with supplements by CAS since 1922, but it will be much wider in scope and will give more details. Instead of just listing journals currently abstracted by $C A$ with current holdings of a particular library, Access will be a cumulative listing with information on holdings of back issues. More than half the participating libraries are large academic libraries, with the inevitable bias towards United States and Canadian libraries. One of the cooperating British libraries is the Chemical Society Library in London. This library has a large number of back issues of journals as well as about 720 current titles in the chemical field.

\section{SCIENTIFIC LITERATURE}

\section{New Style Review}

ThE Quarterly Literature Reports published by Kogan Page Publications are among the most welcome recent additions to the jungle of science journals. For these reviews-at present there are three titles, Surface Activity, Polymers and Clinical Biochemistry-are not just another set of abstracts but selective and, what is more important, critical looks at the mass of literature and patents produced by universities and the chemical industry.

The aim is to attract attention to important papers in each particular field but with a bias towards applications, analytical methods and information on new manufacturing processes. The next issue of Surface Activity, for example, will point out the important safety aspects of a new emulsified aircraft fuel which is far less flammable than conventional fuels. At the moment the compilation of each report is a one man job-Surface Activity is edited by Dr A. J. B. Spaull of Brunel University, Polymers by Dr A. D. Jenkins of the University of Sussex and Clinical Biochemistry by Dr S. S. Szinai of Lilly Pharmaceuticals. According to Academic Press, the distributors, there has been a very good response to the first issue of the reports (subscription cost $f 55 \mathrm{~s}$ a year) and they are confident that the second issue, to be published on May 1, will be equally well received.

\section{FISHERIES}

\section{Whose Salmon?}

THE recent short-sighted and unsportsmanlike practice of drift-netting salmon at their feeding grounds in the Atlantic is arousing fears about the extinction of the species and eausing much gnashing of teeth among the salmon producing countries, who spend vast sums of money on conservation and restocking their rivers only to see the salmon caught before they get home to breed. The obvious solution is to restrict salmon fishing in the Atlantic by international agreement, as has already been done in the Pacific, but Canadian efforts to do this through the International Commission for the North-west Atlantic Fisheries (ICNAF) were frustrated at the last two annual meetings, "partly through ignorance on the part of the majority of the members" and partly by countries such as Denmark and West Germany which have no salmon rivers of their own but a profitable drift-netting industry.

The next ICNAF meeting will be in June, and, in an attempt to persuade the neutral countries that the threat to the salmon is serious, the Atlantic Salmon Research Trust held an international conference in London last week where the statistical evidence of the decrease of salmon stocks was presented. One of the biggest problems the conservationists have to face is that their statistical armoury is not overwhelmingthe best a joint International Commission for the Exploration of the Sea/ICNAF working party, set up last year to investigate the problem "scientifically", could manage was to conclude that "relatively small losses in home water catches in most if not all European countries had taken place because of the West Greenland salmon fishery during the years 1964 to $1967^{\prime}$. and that, despite the heavy restrictions that countries such as Canada, North America, Great Britain, Iceland and Norway have imposed on offshore fishing, this "is increasing rapidly and seems likely to do so both off West Greenland and in other areas". The communication did, however, manage to persuade the participants that the salmon, with their five to eight year reproduc- 